\title{
Formação de professores e os limites e possibilidades das tecnologias digitais na educação ${ }^{1}$
}

\author{
Adilson Cristiano Habowski² \\ Elaine Conte ${ }^{3}$
}

Helen Rose Flores de Flores ${ }^{4}$

\section{Resumo}

O artigo, de bases hermenêuticas, apresenta alguns desafios comuns à formação de professores e esboça projeções tecnológicas descentralizadas na educação. Partimos das seguintes problematizações: De que forma é viável articular uma formação de professores para o planejamento com as tecnologias, indo além dos tecnicismos e do ensino unidirecional? Quais os desafios que as profundas transformações trazem nas formas de se relacionar com o outro no mundo tecnológico na educação? Os resultados indicam que não se trata simplesmente de garantir que as inovações tecnológicas entrem na cultura escolar, mas de dar condições de tempo para que os professores possam pensar, aprender com o outro e ressignificar o antigo, resistindo ao ensino fabricado e integrando as potencialidades humanas.

Palavras-chave: Formação de Professores; Tecnologias; Planejamentos.

\section{Teacher training and the limits and possibilities of digital technologies in education}

\section{Abstract}

The article, based on hermeneutic bases, presents some challenges common to teacher education and outlines decentralized technological projections in education. We start from the following problematizations: How is it feasible to articulate a teacher training for planning with technologies, going beyond technicalities and unidirectional teaching? What challenges do profound transformations bring in the ways of relating to each other in the technological world in education? The results indicate that it is not simply a question of ensuring that technological innovations enter the school culture, but of giving conditions of time for teachers to think, learn from the other and resignify the old, resisting the manufactured teaching and integrating human potentialities.

Keywords: Teacher Training; Technologies; Planning.

\section{Consideração iniciais}

A crescente presença e utilização das Tecnologias Digitais (TDs) em forma de transposições curriculares da educação presencial para uma pedagogia da presença virtual pode promover a superficialidade dos vínculos ou artificialidade das relações formativas e

\footnotetext{
${ }^{1}$ Esta pesquisa conta com o financiamento do Conselho Nacional de Desenvolvimento Científico e Tecnológico (CNPq) e da Fundação de Amparo à Pesquisa do Estado do Rio Grande do Sul (FAPERGS).

2 Universidade La Salle, Canoas, adilsonhabowski@hotmail.com

${ }^{3}$ Universidade La Salle, Canoas, elaine.conte@unilasalle.edu.br

${ }^{4}$ Universidade Federal do Rio Grande do Sul e Universidade La Salle, Canoas, helen.flores@ufrgs.br
} 
pedagógicas, a ponto de provocar confusões do que seja a tarefa da educação, a saber, o desenvolvimento das potencialidades e dimensões humanas. Essas tecnologias ocasionam o acesso cada vez mais fácil e instantâneo às informações, fator que impacta diretamente na cultura escolar, no planejamento e na performance do professor, para que possa dar conta dessa realidade dinâmica e desorientada e, ainda assim, impulsionar os processos de ensino e de aprendizagem. Afinal, que consequências e implicações as TDs podem acarretar à formação pedagógica?

Além disso, as políticas educativas atuais reafirmam a formação profissional como um mecanismo de reprodutibilidade mecânica e inadiável para o exercício da docência e as escolas atuam no sentido de atender as demandas das novas tecnologias do mercado, incorporando-as ao ser humano. Nogueira (2003, p.22) afirma que as políticas de formação de professores “[...] têm como objetivo central ajustar o perfil do professor e a formação docente às demandas do novo mercado de trabalho, em um período marcado por novos padrões de produção, no interior da reestruturação da forma de acumulação capitalista". Os recursos tecnológicos não podem ser usados na educação apenas para operacionalização técnica e travestidos de neutralidade, pois todo conhecimento é político e enraizado historicamente, embora revelem na contemporaneidade uma espécie de tempo irrefletido e pasteurizado das conexões tecnológicas, talvez por mudanças abruptas e desconhecidas que atravessam o campo da educação. Especialmente quando se menciona as experiências pungentes de uma educação online que vem sendo imposta por escolas e universidades privadas, em tempos de pandemia, com diferentes gerações e arranjos marcados por aulas em salas de webconferência, nas quais os microfones e câmeras dos estudantes são desligados desde a chegada. Num modelo falsamente universal de uma inclusão digital (sem acesso à internet e à infraestrutura básica), sem processos de articulação da escola com a conversa cotidiana ou debates críticos em termos de ambiências formativas. Ou seja, com experiências calcadas em pressões e exigências calcadas em uma metodologia instrucional, curriculista, massiva, mediada com materiais didáticos, de autoestudo (praticamente sem relacionamento em comunidade escolar ou cooperação), com um curto tempo de liberação para o diálogo com a vida ou com inúmeros condicionamentos remotos e aligeirados.

No transcorrer da história, acreditava-se que com o aparecimento de novas tecnologias 
se aperfeiçoaria os processos de ensinar e de aprender, e ainda permanecem as projeções de que as TDs são capazes de apresentar soluções rápidas para a avanço da qualidade na educação. Mas, se os processos de ensinar e aprender estivesse vinculado às tecnologias, já teríamos há longa data descoberto as soluções para evitar a repetição da barbárie e da violência que assola a dignidade humana, talvez porque ela não se traduz na forma de isolamentos impostos à humanidade. Podemos fazer analogias com o livro didático, ao compreendê-lo enquanto tecnologia que se tornou objetificado quando utilizado como meio de cópia e reprodução integral nos cadernos escolares, ou como uma ação pedagógica unidirecional que visa constranger o outro a fazer interpretações de modelos fixos. Já o quadro negro, uma das tecnologias de grande impacto na educação do século XIX, hoje foi substituído pela lousa digital, assim como os livros impressos pelos eletrônicos (e-books), democratizando, de certa forma, o acesso aos conhecimentos. Diante disso, precisamos questionar a respeito de quais são os limites das TDs para o mundo pedagógico e humano.

Os progressos tecnológicos passam a significar grandes problemas nos contextos educativos quando são tomadas com fim em si e acompanhados pela velocidade e as exigências capitalistas. Ou ainda são impostos e transpostos na sala de aula de modo superficial, como máquinas de educar, de simples adequação, o que não qualifica as experiências pedagógicas. A aceleração sem limites, inclusive dos processos de ensino, passa a esvaziar o sentido das relações humanas e das experiências dialógicas da tradição sociocultural própria do mundo da vida, em nome de uma cultura administrada pelos meios técnicos e de produção competitiva. O fato é que a escola continua tributária de métodos arbitrários de ensino e de reprodução de saberes disciplinares desde outras tecnologias como o livro e o quadro-negro. Nesse processo, as tecnologias evoluem rapidamente e quando os professores buscam inovação simplesmente substituem uma tecnologia por outra, sem passar pelo processo de ressignificação no contexto pedagógico.

Os professores não estão conseguindo coordenar suas ações em tempos de domínio instrumental, recaindo também na dependência tecnológica do próprio progresso. O resultado é uma inversão em termos de autoridade, pois os professores vivem em uma separação desesperadamente solitária com as diferentes funções de tecnologias, alienando-se inclusive do mundo dos estudantes. Na verdade, os professores precisam entender a importância da 
constante reflexão e ação sobre os limites das tecnologias que automaticamente se estabelecem entre os sujeitos, para exercerem a autorreflexão crítica da realidade, por meio de diálogos abertos e interdependentes, reconfigurando trabalhos pedagógicos de estímulo para as diversas experiências que permitam constante (re)visitação, (re)elaboração e a (re)construção nos processos de ensino e aprendizagem. É preciso resistir a uma educação domesticadora enquanto operacionalidade técnica e apropriação instrumental para a eficiência mercantil, o rendimento e o êxito, subvertendo as noções de formação, tempo e pertencimento.

Tendo em vista as mudanças tecnológicas e as necessidades seguidamente impostas à educação, lançamos a seguinte problemática: De que forma é viável articular uma formação de professores para o planejamento com as tecnologias, indo além dos tecnicismos e do ensino unidirecional? Diante das profundas alterações que trazem significados e valores diferentes também sobre as manifestações da vida humana, quais desafios essas rupturas nas formas de se relacionar com o outro no mundo tecnológico e digital lançam na esfera educacional?

A pesquisa tem seu alicerce na abordagem hermenêutica, que nos possibilita diferentes formas de conhecer e interpretar a realidade, reconhecendo o outro na circularidade das relações para a reconstrução de caminhos que possibilitam a construção do diálogo necessário ao aprender conjunto, na busca de sentido que é plural e sempre renovado das tecnologias humanas. Na visão de Hermann (2002, p.28), "a hermenêutica é a arte de compreender, derivada de nosso modo de estar no mundo". Essa compreensão, por sua vez, inclui além desse processo de compreensão e interpretação, sua aplicação, como um momento essencial e integrante desse processo de educar que pressupõe abertura ao outro (GADAMER, 1977). A virtude hermenêutica na educação é para interpretar e compreender os desafios das tecnologias nos planejamentos dos professores, na tentativa de dialogar, reconhecer as diferentes perspectivas de análise dessa gênese e jogar luzes ao problema dos limites à reconstrução de caminhos pedagógicos (HABOWSKI; CONTE; TREVISAN, 2019). As lacunas das tecnologias no campo da formação cultural e educativa têm uma chance de superação por meio de uma racionalidade aprendente, hermenêutica, onde a verdade é conduzida pelas relações do discurso e da linguagem com o mundo, privilegiando os sujeitos para uma interpretação contextualizada. 


\section{Educação e tecnologias: formação pedagógica para além do sentido tecnocrático}

No entendimento de que o professor é o mediador e provocador do encontro do estudante com o objeto de conhecimento, Libâneo (2001, p.22) considera que o professor é responsável por introduzi-los “[...] no mundo da ciência, da linguagem, para ajudar o aluno a desenvolver seu pensamento, suas habilidades, suas atitudes". Portanto, para que possa dar conta com qualidade dessas responsabilidades, há que se investir ainda mais na pesquisa sobre a formação dos profissionais da educação, de modo a:

[...] contemplar a preparação daqueles profissionais da área educacional demandados pela sociedade brasileira, em sua configuração atual, para atuarem na organização e na gestão de todos os segmentos do sistema nacional de ensino. Com igual insistência, é também necessária a formação de estudiosos que se dediquem à construção do conhecimento científico na área, uma vez que a educação também é considerada como um campo teórico-investigativo e que a produção desse conhecimento é requisito fundante de toda formação técnica e docente (LIBÂNEO, 2001, p.15).

As demandas de um conhecimento pedagógico, como caracteriza Libâneo (2001, p.23), exigem que o professor tenha "[...] capacidade de decisão, conhecimentos operativos e compromissos éticos, [para tanto, essa] inserção do pedagogo na condição pós-moderna o obriga a uma abertura científica e tecnológica, de modo a desenvolver uma prática investigativa e profissional interdisciplinar". Takahashi $(2000$, p.45) salienta também o papel da educação diante das tecnologias:

A educação é o elemento-chave na construção de uma sociedade baseada na informação, no conhecimento e no aprendizado. Parte considerável do desnível entre indivíduos, organizações, regiões e países, deve-se à desigualdade de oportunidades relativas ao desenvolvimento da capacidade de aprender e concretizar inovações. Por outro lado, educar em uma sociedade da informação significa muito mais que treinar as pessoas para o uso das tecnologias de informação e comunicação: trata-se de investir na criação de competências suficientemente amplas que lhes permitam ter uma atuação efetiva na produção de bens e serviços, tomar decisões fundamentadas no conhecimento, operar com fluência os novos meios e ferramentas em seu trabalho, bem como aplicar criativamente as novas mídias, seja em usos simples e rotineiros, seja em aplicações mais sofisticadas. Trata-se também de formar os indivíduos para aprender a aprender, de modo a serem capazes de lidar positivamente com a contínua e acelerada transformação da base tecnológica.

Periódico Horizontes - USF - Itatiba, SP - Brasil - e020029 
Nessa perspectiva de atuação investigativa e interdisciplinar, como meio de abertura aos novos desafios, Libâneo (2011) entende que o professor precisa assumir seu papel social e atuante na formação cidadã dos estudantes. Para tanto, precisa estar ciente da responsabilidade e importância da sua atuação para o desenvolvimento das potencialidades do espaço de atuação, pois por meio de um novo posicionamento e relações frente aos conhecimentos amplia o direito de liberdade e a inteligência cognitiva e emocional, em consonância com a postura autorreflexiva de Freire (2005), numa perspectiva de emancipação coletiva. Nesse sentido, é necessário que o professor tenha abertura e flexibilidade para dialogar com outras práticas, planejamentos e estratégias pedagógicas, com vistas a propiciar ao estudante a reconstrução do conhecimento tecnológico, muitas vezes, de concepções materialistas na educação, em prol de uma transformação autocrítica, de "[...] valorização do vínculo entre o conhecimento científico e sua funcionalidade na prática" (LIBÂNEO, 2011, p.89).

$\mathrm{Na}$ tentativa de trazer à tona os desafios à formação e à desvalorização do professor, em decorrência de processos como tecnologização, privatização e racionalização do ensino, Nóvoa (2000) defende a necessidade de uma retomada da dimensão crítica, da reflexão e da vigilância constante por parte dos envolvidos no cenário da educação. Essa questão é importante para que possamos repensar o papel do professor frente às novas formas de relações com os conhecimentos, que não se resume ao manejo dos instrumentos, mas que implica reconhecer as mudanças humanas, sociais e tecnológicas, iniciadas nas últimas décadas. Tais mudanças na sociedade refletem na alteração do perfil dos estudantes em diferentes níveis de ensino, agravadas pela presença massiva e o acesso facilitado às TDs, que obrigam as instituições formadoras a rever sua tradicional forma de relação com os estudantes, visto que "hoje grande parte desse conhecimento já não está na Universidade. Está na Internet, nos meios de comunicação interativa, em muitos lugares, mas não está mais na Universidade" (NÓVOA, 2000, p.132). Tal facilitação acaba negligenciando a abertura ao outro para aprender, e na heterogeneidade de relações e conhecimentos, perde-se o essencial das interações escolares, ou seja, que só através do diálogo aprendemos a revisar nossa atuação prática e formativa, visto que questionamos e dialogamos com as diferentes relações pedagógicas, planejamentos e formas de ver o mundo (NÓVOA, 2000).

O autor é defensor de um fazer reflexivo e inverte as preocupações vigentes, deslocando 
a atenção exclusiva dos saberes daquele que ensina para aqueles que serão ensinados. Nóvoa (1992, p.134) argumenta que o professor irá perceber "[...] a necessidade imperiosa de fazer uma reflexão sobre o sentido do seu trabalho. Seria necessário que essa reflexão tivesse, simultaneamente, uma dimensão individual (autorreflexão) e uma dimensão coletiva (reflexão partilhada)". Essa possibilidade reflexiva proposta por Nóvoa (2000, p.134), depende da abertura ao outro das instituições formadoras, assim como das necessidades de mudança, promovendo situações para a constituição de "[...] grupos de reflexão pedagógica, dentro das universidades, que conduzam pouco a pouco a instaurar rotinas de debate, de supervisão, de formação interpares". Se antes do planejamento, o professor possuir a abertura de gerar questionamentos entre os professores e compreender a necessidade de fazer uma reflexão sobre o sentido do seu trabalho social, será viável essa tomada de decisão no voltar-se para si e (re)avaliar suas práticas constantemente. Isso também exige que o professor e o contexto em que atua estejam cientes de que sua formação não é constituída "[...] por acumulação (de cursos ou de conhecimentos), mas através de um trabalho de reflexividade crítica sobre as práticas e de reconstrução permanente de uma identidade pessoal" (NÓVOA, 1992, p.25). Identificar o que realmente constitui o formar-se professor perpassa pelo entendimento de questões basilares que envolvem, sobretudo, a personalidade humana e o ato de educar como um princípio científico e educativo, pois:

[...] a capacidade de compreender o saber, o modo como ele se constitui historicamente, os momentos de virada de uma determinada disciplina, as vias alternativas que poderia ter seguido etc. É aqui, nesta compreensão do modo como os saberes se organizaram e reorganizaram que reside a essência da formação universitária. Estamos perante um processo longo, que tem uma parte "informativa" (de aquisição dos saberes), mas que tem também uma dimensão histórica, crítica e, pelo menos na formação pós-graduada, uma dimensão de participação na própria produção de conhecimento científico (NÓVOA, 2000, p.135-136).

A cultura educacional precisa estar ciente de que "não há ensino de qualidade, nem reforma educativa, nem inovação pedagógica, sem uma adequada formação de professores", de professores prático-reflexivos, dotados de conhecimentos e experiências comunicativas plurais, para dar as condições de possibilidade para criação livre no encontro com o outro 
(NÓVOA, 1992, p.9). Mas essa construção perpassa pelas condições de possibilidade que lhes são fornecidas na caminhada formativa, propiciando momentos para refletir sobre a própria prática e processo de conhecer, de forma constante e evolutiva. O processo educacional envolve sujeitos com níveis diferentes de conhecimentos, mas que estão dispostos a compartilhar esses conhecimentos, sendo o professor o impulsionador das situações de ensino que subsidiam esse compartilhamento de saberes. Gatti $(2016$, p.163) considera que "[...] a formação de quem vai formar torna-se central nos processos educativos formais, na direção da preservação de uma civilização que contenha possibilidades melhores de vida e coparticipação de todos". Defende ainda que os problemas socioeconômicos, culturais e científicos recorrentes na educação, em especial, com a formação do professor, são determinantes na produção das desigualdades, pela "passagem de uma sociedade industrial para uma sociedade da informação, de uma sociedade segura para uma sociedade plural e instável está gerando crises diversas" (GATTI, 2016, p.165).

Sob esse ponto de vista, Gatti (2016, p.170) reforça a necessidade de considerar na formação de professores e no contexto cultural global, além do fato de que o professor também está inserido nesse contexto e nas dimensões locais, cuja atuação e formação perpassa por “[...] eixos sócio-filosóficos, mas se faz na heterogeneidade das condições geográfico-culturais deste território", a relevância de desenvolver, sobretudo, as potencialidades humanas da constituição docente. Reforçando o entendimento de Gatti (2016) sobre os aspectos locais, atuais e sociais, os quais devem ser considerados na formação de quem forma, em meio às interferências nas práticas de sala de aula em tempos de presença de TDs, Barreto (2017) alerta para um discurso, quase hegemônico, que tende a sustentar as bases políticas, programas e projetos de inserção das tecnologias na educação e, por conseguinte, a capacitação do professor. Em suas palavras, é errônea a correspondência de que:

[...] quanto maior a presença da tecnologia, menor a necessidade do trabalho humano, bem como maior a subordinação real do trabalho ao capital e aos que se valem das tecnologias para ampliar as formas de controle do trabalho e dos seus produtos. Com ele, é fortalecida a racionalidade instrumental que, presidindo o movimento, resulta na perda da perspectiva da totalidade do trabalho docente, com o privilégio dos meios, em detrimento das mediações (BARRETO, 2017, p.127). 
Nesse processo, entendemos que na relação tensa entre formação de professores e TDs, há que se considerar a heterogeneidade cultural e social de professores e estudantes (GATTI, 2016), como forma de combinar ações de justiça cognitiva variadas e possibilidades de ambiências formativas via educação a distância. Portanto, reconhecer que o espaço educativo está em constante movimento formativo, sendo necessário fornecer o desenvolvimento de relações pedagógicas diferentes das que existem hoje, ou seja, uma postura aprendente, indagadora, provocadora, atenta e observadora por parte dos professores (NÓVOA, 2000). Entretanto, essa movimentação em rede cultural requer uma prática investigativa e profissional interdisciplinar e contextualizada, como meio de abertura científica, tecnológica e de processos formativos digitais, como integração social, cognitiva e cultural (LIBÂNEO, 2001). Contudo, “[...] não se trata mesmo de substituir os professores pelas TIC", mesmo que essa concepção tenha pautado as novas investidas curriculares, mas, operar "[...] mudanças profundas a ponto de reconfigurar todo o processo, da formação ao exercício profissional”. (BARRETO, 2017, p.129).

Nesse sentido, considera-se primordial uma formação baseada no exercício da percepção dos significados acerca do mundo, que advenha das necessidades práticas contextuais, promovendo a aprendizagem nas diferentes áreas (sensorial, vida prática, linguagem, matemática etc.), para que se favoreça a reconstrução de experiências interdisciplinares relacionadas às TDs nos múltiplos cenários de ensino e de aprendizagem. As práticas pedagógicas em redes de pesquisa colaborativas surgem como perspectivas às construções de práticas interdisciplinares, pois colocam em ação o trabalho cooperativo interpares sobre os conteúdos. Tal mecanismo de interação é um trabalho feito de pesquisas, reconhecido pelo comprometimento de todos, na (re)construção de conhecimentos, na renovação curricular e está afinada com as demandas sociais e tecnológicas que se metamorfoseiam de forma constante. Porém, é preciso olhar na raiz desse dilema a falta de formação que está diretamente ligada às condições de trabalho.

A questão da formação de professores não pode ser dissociada do problema das condições de trabalho que envolvem a carreira docente, em cujo âmbito devem ser equacionadas as questões do salário e da jornada de trabalho. Com efeito, as condições precárias de trabalho não apenas neutralizam a ação dos professores, mesmo que fossem bem formados. Tais condições dificultam também uma boa formação, pois operam como fator de desestímulo à procura pelos cursos de formação docente e à dedicação aos estudos (SAVIANI, 2009, p.153).

Periódico Horizontes - USF - Itatiba, SP - Brasil - e020029 
Tendo em vista a diversificação das atividades educativas e, consequentemente, a ampliação das demandas educacionais na sociedade, Libâneo (2001, p.20) define a contemporaneidade como "genuinamente pedagógica", visto que "[...] a escola é ainda a chance de acesso ao mundo do conhecimento, para fazer frente ao mundo da informação. Informação e conhecimento são termos que andam juntos, mas não se equivalem". Nessa compreensão, é preciso compreender que as TDs estão provocando mudanças nos métodos tradicionais de ensino, o que nos remete, novamente, para o fato de que a informação é um caminho de acesso aos conhecimentos, mas que por si só não projeta o saber. Nota-se que a renovação da educação está intimamente ligada à renovação do próprio sujeito e da cultura, pois necessita de um processo autocrítico da própria formação humana, base que reforça uma restruturação de carreira, que leve em consideração os conhecimentos já acumulados no exercício profissional, como possibilite a atualização docente em consonância com as exigências da sociedade do século XXI (LIBÂNEO, 2001). O acesso e o emprego das tecnologias nas escolas acontecem seguidamente por vertentes de conteúdo técnico-pedagógico, normalizadoras e operacionais, que tendem a homogeneizar e fragilizar as experiências dos professores, gerando reflexos imediatos no planejamento pedagógico que nutre uma certa rigidez e estabilidade, pois abandona o diálogo e a busca de sentido que é plural.

Por tudo isso, a educação tecnológica precisa ser (re)pensada na formação de professores como um espaço de ingresso na vida pública e uma condição para produzir um profissional que saiba mediar mundos, integrar diálogos interculturais e reconstruir saberes com os outros, sem abandonar o controle do processo de conhecer por meio das tecnologias. A ressignificação na formação de professores não pode sucumbir ao canto do neoliberalismo, mas precisa aproximar e dar visibilidade aos atores sociais e garantir ações articuladas em políticas alicerçadas num mundo onde a questão do engajamento tecnológico, da igualdade social e da cidadania não sejam apenas discursos fabricados e vazios de sentido humano.

Nessa perspectiva, Pugens, Habowski e Conte (2018, p.7) afirmam que existem fragilidades na formação de professores e não apenas no manuseio das tecnologias, "mas também no potencial relegado a outras esferas constitutivas do mundo social (da era da informação) que é de ser um profissional reflexivo, pois este fará pensar outras possibilidades por meio destas ferramentas de maneira crítica e emancipadora". A formação docente é o maior 
desafio hoje enfrentado em termos de reorganização curricular, pois o trabalho docente vai muito além do princípio da escrita e da oralidade, perpassa a transmissão e recriação de conteúdos culturais e o estímulo constante a novos horizontes de investigação humana, despertando a busca e as inter-relações com o conhecimento. A formação é, segundo Nóvoa (1992, p.18):

[...] mais do que um lugar de aquisição de técnicas e de conhecimento, a formação do professor é um momento chave da socialização e da configuração profissional, ou seja, a formação do educador vai além da metodologia das receitas prontas que não contêm sentido, mas vai ao encontro da troca, do compartilhamento e da busca pela construção do conhecimento.

A formação se constrói na prática e implica compreender os mecanismos de interação humana que estão em constante relação com as TDs e midiáticas, cujas mudanças sucessivas e nessa renovação histórica e cultural, as frequentes reconfigurações da palavra, da escrita e das práticas cotidianas, torna-se um meio de socialização e reflexão (CASTELLS, 2007). Nesse cenário desenvolvemos novas gestões do conhecimento, atribuindo diferentes formas de simbolização e representação tecnológica, cuja complexidade é apresentada em novos produtos e processos à formação docente. As TDs aliadas a esta formação global podem ser consideradas elementos de renovação dos canais comunicativos e da inter-relação entre o sujeito, a cultura e o mundo (CONTE; HABOWSKI, 2019). O paradigma tecnológico vem modificando as ações, ditando as regras do mercado, acelerando comportamentos e transformando a educação contemporânea. Para Castells (2007, p.69),

O ciclo de realimentação entre a introdução de uma nova tecnologia, seus usos e seus desenvolvimentos em novos domínios torna-se muito mais rápido no novo paradigma tecnológico. Consequentemente, a difusão da tecnologia amplifica seu poder de forma infinita, à medida que os usuários apropriam-se dela e a redefinem. As novas tecnologias da informação não são simplesmente ferramentas a serem aplicadas, mas processos a serem desenvolvidos. [...]. 0 que pensamos e como pensamos é expresso em bens [...], educação ou imagens.

Então, tudo leva a crer que não se trata de buscar e desenvolver novos dispositivos e inovações tecnológicas, mas de saber aprender a engajar suas potencialidades a favor da 
educação, de forma significativa para a aprendizagem dos estudantes. Trata-se de explorar a tecnologia a partir de um propósito coerente, num exercício de poder comunicativo e autocrítico. Na visão de Castells (2007), vivemos em um mundo que se tornou digital e a sociedade está sendo cada vez mais organizada em torno dessas tecnologias e do poder tecnológico que exerce no mundo global. Tais influências também afetam a educação, o mundo trabalho e as relações e sociais, pois interfere na comunicação e nos modos de ser, de sentir e agir do professor, do qual depende a qualidade da educação (CONTE; HABOWSKI; RIOS, 2019).

A necessidade de refletir sobre os processos educativos e de inclusão tecnológica é fundamental para compreender as modificações, as novas significações e as contradições assumidas nas experiências de ensino que envolve as tecnologias. As experiências educativas com as tecnologias são uma realidade em muitos contextos, mas que pode surgir como simples dominação da técnica condicionada, esquecendo que todo conhecimento é dirigido por interesses técnicos, práticos ou emancipatórios (HABERMAS, 1975). Com a facilidade de compra, muitos estudantes têm acesso às tecnologias que são desejadas e introjetadas como modismos, fetiches da mercadoria. Daí a relevância da prática social de educar que surge como possibilidade de resistência, de pesquisa e de posicionamento crítico diante das informações. É uma tentativa de ir além de um imperativo de modernização disfarçada, pois, muitas vezes, sequer conseguimos explorar todas as funcionalidades dos aparelhos, atitude essa que compactua com a manutenção da simples instrumentalidade e controle da tecnologia. Afinal de contas, a educação tecnológica não pode se esgotar na transmissão de conhecimentos, mas implica no exercício de liberdade cooperativa para a reconstrução e ressignificação de conhecimentos, obviedades e pré-juízos.

Assim, a tecnologia digital "não mais pode ser definida como uma somatória de novas técnicas operacionais, mas sim como um modus vivendi, como um processo social que determina as configurações identitárias dos indivíduos e as do processo educacional/formativo". (ZUIN, 2010, p.961). As (TDs) podem estar interligadas em rede global, em um meio de troca de informação e de realização de ações cooperativas, sendo possível também entrar em contato com pessoas de outras culturas e trocar ideias, conhecimentos, conseguir auxílio na resolução de problemas ou mesmo contribuir com um grupo na elaboração de uma tarefa complexa (VALENTE, 2014). Esses recursos tecnológicos proporcionaram aos professores e estudantes 
intercâmbios e outras formas de usar as tecnologias para desempenhar a autoria coletiva, passando de consumidores a produtores de informação, o que tem motivado e causado mudanças em sala de aula. Com isso, se faz necessário analisar o cenário e as características da formação de professores, buscando verificar se vem adotando velhos padrões de ensino ou se tem um caráter educativo, que vai além do instrumental para preparar mão de obra para o mercado capitalista. A formação permanente em meio à autocrítica tecnológica está possibilitando nos processos educativos esses encontros com a pluralidade de visões de mundo e a diversidade cultural.

Para Conte, Habowski e Rios (2018, p.1), “as novas tecnologias estão modificando o mundo no qual vivemos de forma rápida e inovadora, mas ao mesmo tempo carecem de ações pedagógicas contextualizadas e integradas na direção de uma transformação social à construção de formas de convivência". Portanto, a tecnologia na educação e a inclusão digital estão intimamente ligadas através de um contexto social complexo. Parafraseando Sibilia (2012), a escola em tempos de dispersão pode criar redes ou paredes, ainda não sabemos como continuará esta (re/in)evolução da tecnologia na educação, tamanha a velocidade com que se expande, bem como a real interface comunicacional em relação ao processo formativo. Talvez seja uma das características mais instigantes de viver nessa época: a aventura de sermos contemporâneos de uma cultura digital (SIBILIA, 2012).

As discussões sobre as TDs e as potencialidades e limites ao aprender com elas estão lançando desafios à construção de questionamentos e reflexões mais profundos de dimensões socioculturais. Nessa perspectiva, Pretto (2012) diz que as políticas da educação precisam encaminhar ações rumo à conexão social com o outro, promovendo a implementação de softwares livres e abertos, em sintonia com as conexões de banda larga. No entanto, para que sejam incluídos nos currículos e espaços escolares convém a todas as instâncias formativas ficarem atentas para as distintas lógicas de pensar em planejamentos colaborativos. Para Rodrigues, Almeida e Valente (2017, p.63),

$\mathrm{Na}$ formação de professores, inicial ou continuada, o uso de narrativas digitais de aprendizagem pode contribuir para a integração entre as TDIC e os currículos e promover práticas pedagógicas mais autorais [...], abrindo caminho na contramão de um cenário educacional de uso excessivo de material apostilado, 
currículo prescrito com ênfase em listas de conteúdos e voltado mais às avaliações e ranqueamentos do que ao processo formativo, entre outros fatores, que têm tornado os professores da educação básica cada vez mais tarefeiros com vistas ao cumprimento das atividades curriculares prescritas.

As condições de trabalho e os cursos de formação não vêm assegurando atividades emancipatórias nas escolas. Rodrigues, Almeida e Valente $(2017$, p.63) afirmam que no cenário tecnológico, "o professor é preparado pela repetição, pelo apostilamento e pela cópia. Como, então, poderá preparar seus alunos de maneira diferente, com práticas promotoras de autoria, posicionamento crítico e empoderamento dos sujeitos?". Tais fragilidades são percebíveis nos currículos dos cursos de licenciatura, em que "as poucas disciplinas que tratam desse tema possuem, de um modo geral, um caráter instrumental, não envolvendo a relação das tecnologias com o contexto social e político, nem as potencialidades das mesmas" (BONILLA; PRETTO, 2011, p.65). Por essa razão, é necessário que os professores tenham uma formação intelectual mais ampla, que seja capaz de contemplar as problemáticas e complexidades do mundo das tecnologias, tendo em vista a ideia do mundo virtual de integrar o trabalho do professor. É necessário entender que muitos dos professores são fruto de uma educação bancária, sem a presença das tecnologias ou sem a possibilidade de ressignificá-las como forma de pensar os conhecimentos (FREIRE, 2005).

Essa ausência de reflexão crítica apresenta fragilidades no processo de ensino e aprendizagem colaborativa dos professores, dificultando na elaboração de planejamentos pedagógicos mais autorais e menos reprodutores, cuja marca é a autonomia e a interdependência comunicativa. Contudo, percebemos que embora persistam os resquícios de uma educação fragmentada e descolada da realidade, sob o princípio da mera transferência de saberes técnicos, as perspectivas educacionais tradicionais que atribuíam ao professor o responsável por todo o processo de ensino estão colocadas em xeque pelas projeções descentralizadas que as TDs provocam, e que demanda um olhar sempre renovado no contexto atual da formação de professores. Trata-se de dar sentido às tecnologias a partir de intencionalidades pedagógicas coerentes com o exercício do poder comunicativo e (auto)crítico, pois a tecnologia não pode ser tomada como um fim em si, mas como um meio provocativo, reflexivo e de abertura para os processos de ensino e de aprendizagem. 


\section{Considerações finais}

Os desafios da formação de professores são interdependentes das ações humanas e dos planejamentos das aulas com as tecnologias digitais no campo educacional que possam suscitar maior sensibilidade em face da existência. É preciso compreender que a evolução educativa não se refere apenas ao suporte técnico-instrumental e da produção de conteúdos (gravar videoaulas por exemplo), mas usar os conteúdos já disponíveis online e fazer uma curadoria desses materiais existentes, aprimorando o ato de pesquisa, de ressignificação do exercício de cidadania e de recriação pedagógica, para pensar outras atividades e potencializá-las de forma inteligente e interdisciplinar. Os professores se vêm obrigados a repensar seus planejamentos educacionais em meio a tantas mudanças decorrentes dessa gestão compartilhada do conhecimento, que está vinculada aos interesses políticos, tecnológicos, econômicos e midiáticos. Isso tem reflexo direto na formação humana, já que todos somos afetados e precisamos participar de uma educação que nos humanize e não nos fragilize ainda mais. Os professores esquecem que os artefatos tecnológicos funcionam de fora para dentro, armazenam e processam informações, não conseguindo interpretar os conhecimentos em relação dialógica com os saberes e as formas de vida (HABOWSKI, 2019). Desta forma, concluímos que a inserção mecânica das tecnologias em sala de aula não resolverá as fragilidades das aprendizagens, sendo necessário "necessário não apenas investir em equipamentos e formação de professores, mas antes de tudo reinventar a pedagogia com base em estudos e pesquisas que ajudem a compreender como as crianças [estudantes] aprendem hoje" (BELLONI; GOMES, 2008, p.726). Além disso, a ressignificação dessa problemática na formação de professores não pode sucumbir às arenas do mercado e da produção, mas precisa aproximar e dar visibilidade aos atores envolvidos e às práticas sociais de educar.

Considerada a importância de uma reflexão constante sobre os limites e possibilidades das tecnologias na cultura digital, reafirmamos a necessidade de formação de professores para uma mudança de roteiro em relação ao sentido educativo das tecnologias, que ultrapasse o domínio da instrumentalização e tenha alicerces na reflexão compartilhada, de abertura para novos sentidos, para a (re)construção e ressignificação dos fazeres e saberes, que viabilize aos 
professores experiências capazes de transformações das relações sociotécnicas. Nesse sentido, as distintas práticas pedagógicas dos professores têm muito a colaborar com os processos de autorreflexão e os descentramentos comunicativos na educação, que passa também por políticas de incentivo à formação de professores para desenvolver condições mínimas de um planejamento dialógico e de uma prática social de educar, que inclua as TDs para além de um pacote imediatista, descontextualizado das experiências ou de reprodução de um saber sem sentido na cultura escolar ou incompreendido.

\section{Referências}

BARRETO, R. G. Objetos como sujeitos: o deslocamento radical. In: FERREIRA, G. M. S. et al. (org.). Educação e tecnologia: abordagens críticas. Rio de Janeiro: SESES, 2017, p.124-140.

BELLONI, M. L.; GOMES, N. G. Infância, mídias e aprendizagem: autodidaxia e colaboração. Educação \& Sociedade, Campinas, v.29, n.104 [especial], p.717-746, out. 2008.

BONILLA, M. H.; PRETTO, N. L. (org.). Inclusão digital: polêmica contemporânea. Salvador: EDUFBA, 2011.

CASTELLS, M. A era da informação: economia, sociedade e cultura - vol. 1: a sociedade em rede. 6.ed. São Paulo: Paz e Terra, 1999.

CONTE, E.; HABOWSKI, A. C.; RIOS, M. B. As tecnologias na educação: perspectivas freireanas. In: CIET: EnPED: educação e tecnologias: pesquisa e produção de conhecimento, 2018, São Carlos. Anais [...]. São Carlos, 2018. v.4. p.1-12. Disponível em: http://cietenped.ufscar.br/submissao/index.php/2018/article/view/132. Acesso em: 15 abr. 2020.

CONTE, E.; HABOWSKI, A. C.; RIOS, M. B. Ressonâncias das tecnologias digitais na educação. Revista Ibero-Americana de Estudos em Educação, Araraquara, v.14, n.1, p.31-45, jan./mar., 2019. DOI:10.21723/riaee.v14i1.11110.

CONTE, E.; HABOWSKI, A. C. O agir comunicativo na educação como dispositivo e autoridade epistêmica à práxis tecnológica. Educ. Soc., Campinas, v.40, p. 1-17, 2019. DOI:

10.1590/es0101-73302019193424

FREIRE, P. Pedagogia do oprimido. Rio de Janeiro: Paz e Terra, 2005.

GADAMER, H. G. Verdad y método. Trad. Ana A. Aparicio e Rafael de Agapito. Salamanca: Sígueme, 1977. 
GATTI, B. A. Formação de professores: condições e problemas atuais. Revista Internacional de Formação de Professores, Itapetininga, v.1, n.2, p.161-171, 2016.

HABERMAS, J. Técnica e ciência como ideologia. In: Os pensadores, vol. XLVIII. São Paulo: Abril Cultural, 1975, p.45-92.

HABOWSKI, A. C.; CONTE, E.; TREVISAN, A. L. Por uma cultura reconstrutiva dos sentidos das tecnologias na educação. Educação \& Sociedade, Campinas, v.40, n.2, p.1-18, 2019. DOI: 10.1590/ES0101-73302019218349

HABOWSKI, A. C. Teoria crítica da tecnologia e educação: desafios contemporâneos. 2019. 153f. Dissertação (Mestrado em Educação) - Universidade La Salle, Canoas, 2019. Disponível em: http://repositorio.unilasalle.edu.br/bitstream/11690/1249/1/achabowski.pdf Acesso em: 16 abr. 2020.

HERMANN, N.Hermenêutica e educação. Rio de Janeiro: DP\&A, 2002.

LIBÂNEO, J. C. Pedagogia e pedagogos: inquietações e buscas. Educar, Curitiba, n.17, p.153-176, 2001.

LIBÂNEO, J. C. Adeus professor, adeus professora? novas exigências educacionais e profissão docente. São Paulo: Cortez, 2011.

NOGUEIRA, E. S. Políticas de formação de professores: a formação cindida (1995 - 2002). 2003. 198f. Tese (Doutorado em Educação) - Universidade Federal do Rio de Janeiro, Rio de Janeiro, 2003.

NÓVOA, A. A formação de professores e a profissão docente. Os professores e a sua formação. Lisboa: Publicações Dom Quixote, 1992.

NÓVOA, A. Universidade e formação docente. Interface - comunicação, saúde, educação. Entrevista realizada em 18 de abril de 2000 pelas professoras: Miriam Celí Pimentel Porto Foresti e Maria Lúcia Toralles Pereira. 2000.

PUGENS, N. B.; HABOWSKI, A. C.; CONTE, E. Paradoxos da docência em tempos de cultura digital. In: SEMINÁRIO INTERNACIONAL PESSOA ADULTA, SAÚDE E EDUCAÇÃO: a construção da profissionalidade docente: a pessoa em formação (SIPASE), 6., 2018, Porto Alegre. Anais [...] Porto Alegre: EDIPUCRS, 2018. v.4. p.1-9. Disponível em:

http://editora.pucrs.br/acessolivre/anais/sipase/assets/edicoes/2018/arquivos/38.pdf. Acesso em: 15 abr. 2020.

PRETTO, N. D. L. Professores-autores em rede. In: SANTANA, B.; ROSSINI, C.; PRETTO, N. L. (org.). Recursos educacionais abertos: práticas colaborativas políticas públicas. Salvador: Edufba; São Paulo: Casa da Cultura Digital, 2012. p.91-108. 
RODRIGUES, A.; ALMEIDA, M. E. B.; VALENTE, J. A. Currículo, narrativas digitais e formação de professores: experiências da pós-graduação à escola. Revista Portuguesa de Educação, v.30, n.1, p.61-83, 2017.

SAVIANI, D. Formação de professores: aspectos históricos e teóricos do problema no contexto brasileiro. Revista Brasileira de Educação, Rio de Janeiro, v.14, n.40, p.143-155, 2009.

SIBILIA, P. Redes ou paredes: a escola em tempos de dispersão. Rio de Janeiro: Contraponto, 2012.

TAKAHASHI, T. (org.). Sociedade da informação no Brasil: livro verde. Brasília: MEC, 2000.

VALENTE, J. A. A comunicação e a educação baseada no uso das tecnologias digitais de informação e comunicação. UNIFESO - Humanas e Sociais, v.1, n.1, p.141-166, 2014.

ZUIN, A. A. S. O plano nacional de educação e as tecnologias da informação e educação. Educação \& Sociedade, Campinas, v.31, n.112, p.961-980, jul./set. 2010.

Recebido em junho 2019.

Aprovado em maio 2020. 